\title{
Institutional Challenges in the Implementation Process: A Case Study of Rural Transport Accessibility in Kuala Krai, Kelantan
}

\author{
Maria binti Mohd Ismail ${ }^{\mathrm{a}}$ \& Raja Noriza binti Raja Ariffin ${ }^{\mathrm{b}}$
}

\begin{abstract}
The central aim of many transport systems is to improve people's access to goods, services and facilities. Improving transport access can subsequently reduce social isolation. Compared to urban areas, the issue of accessibility is more prominent in rural areas due to its distances from many opportunities. It has been proven in many studies that the provision of rural infrastructure and the improvement of rural transport can upgrade the social well-being of the rural community. The process of improving rural access should always start with the identification of the transportation needs of the community and their mobility patterns. This paper narrates the institutional challenges in implementing rural transport accessibility strategies in Kuala Krai, Kelantan. The district is located in the northeast of Peninsular Malaysia. The qualitative case-study approach used in this study involved 17 respondents; thirteen policymakers from federal, state and local governments, two local transport operators and two rural transport experts. The findings show that among the institutional challenges in the implementation process are poor communication and coordination, lack of transport planning experts and limited financial resources. The findings provide critical inputs for policymakers at various decision-making levels, namely federal, state and local, in planning and designing a more accessible transportation system for the rural population.
\end{abstract}

Keywords: Accessibility; Rural transport; Transport system; Challenges; Implementation.

JEL Classification: H76, H79, R00

a Corresponding author. Department of Administrative Studies and Politics, Faculty of Economics and Administration, University of Malaya, 50603 Kuala Lumpur. Email: maria.ismail@um.edu. $m y$

b Department of Administrative Studies and Politics, Faculty of Economics and Administration, University of Malaya, 50603 Kuala Lumpur.Email: rnoriza@um.edu.my 


\section{Introduction}

In $2050,34 \%$ of the global population is expected to consist of people in the rural areas (UN DESA, 2014). Based on the Rural Access Index (RAI) developed by the World Bank, about one billion of the rural population worldwide would live without reliable transport (World Bank, 2007). The role of transport is to ease the access people have to goods, services and facilities. Hence, the absence of a good transport system will undoubtedly impact the life of the rural people negatively due to the lack of access to opportunities. Transport involves the movement of people and goods for a variety of purposes via any possible means as cited by the International Labor Organisation (2003). Rural transport improvement, together with the provision of rural infrastructure, can improve rural access.

This relationship between transport accessibility and opportunities has been proven in many areas. For instance, the policy objectives in the early years of the Malaysia Plan, which was a plan to guide the development of the country, mentioned improving transport access as a way to improve the socioeconomic conditions of people in rural areas. It has been shown in the subsequent Plans, development and the achievement of the economic objectives was a result of the improvement of the transport system. Most of the world's poor live in rural areas isolated by distance and terrain, which hinders them from accessing employment and economic opportunities, markets, healthcare and education facilities (Starkey \& Hine, 2014). On a similar note, Cook et al. (2017) have mentioned that the lack of dependable rural transport infrastructure (including paths, trails, bridges and roads) and access to available and affordable transport services, have hampered the rural population from gaining economic freedom, creating healthy families, accessing education and actively participating in the community and in national development.

There is an utmost urgency in today's world to have an effective and competent public transportation system. Public transportation is described as the basis of a country's economy in providing adequate access by linking places together, which in turn helps to mobilise citizens to their workplaces, places of education and entertainment facilities (Azmi \& Fanim, 2012). The provision of a transport infrastructure that looks at the need to provide reliable public transportation is a pressing issue in many countries, particularly in the developing world. The policy of providing mainly road 
infrastructure in the rural areas and neglecting public transport services has created a gap in accessibility to opportunities. Those with ownership of a private vehicle have the advantage of accessing opportunities, while the rest are usually left behind and miss the prospect of improving their well-being.

According to Yiu (2017), upgrading rural transport drives sustainable rural development and national growth. Meanwhile, poor rural transport causes the poor to stay disconnected and deprived. Access to markets and employment opportunities through improved rural transport infrastructure and services are critical and crucial pre-conditions to generate rural income to reduce poverty. Countries are incapable of operating competently and developing socially and economically without efficient, affordable, sustainable and appropriate climate-resilient urban, inter-urban and rural transport infrastructure and services (Cook et al., 2017). Meanwhile, a good transport system should not only emphasise reducing the time, distress and effort to access the services, but most importantly develop the services closer to the people by building a suitable network to foster access to the centres in which attractions, services and amenities are concentrated. This contributes to improving connectivity and accessibility between city-to-city linkages, especially in rural areas. By bringing services closer to the people, or making services mobile, the need for travel is reduced. The supply of transport services in the form of vehicles is often overlooked in the planning of infrastructure and accessibility (Ellis, 1997).

Consequently, as stated by Litman (2017), how transportation is evaluated can affect planning decisions. Therefore, it is crucial for transport planning in rural areas to be properly coordinated, designed, implemented and maintained together with the involvement of the community. According to Suruhanjaya Pengangkutan Awam Darat (SPAD) (2012), public transport accessibility problems and the execution of integrated rural transport systems in Malaysia have stressed the importance of having robust collective planning that involves all the three layers of the government (federal, state, and local authorities). Due to the lack of inclusive planning, public transport services are pictured as ineffective and have failed to be accessed by all. This notion is supported by Ngah (2015), who adds that planning mechanisms and rural policies at the regional and local levels are still lacking in Malaysia. Thus, this study attempts to explore the institutional challenges in implementing rural transport initiatives in Kuala Krai, Kelantan.

In the rural areas of Malaysia, specifically Kuala Krai, people are 
connected to their destinations only by limited train and bus services. The Kuala Krai district falls under the administration of two local authorities, namely the Kuala Krai District Council (Majlis Daerah Kuala Krai, MDKK) that controls the northern area of Kuala Krai, while Dabong District Council (Majlis Daerah Dabong, MDD) controls the southern part of the district. MDKK administers the main town of Kuala Krai in the Batu Mengkebang sub-district, while MDD controls the Dabong and Olak Jeram sub-districts, that are remote areas in Kuala Krai. The present road system in Kuala Krai is reported as incomprehensive as some areas are not connected with an accessible road system (Kuala Krai Local Plan, 2010-2020). The local train that is scheduled to fetch school children daily is limited and is also offered to meet the local people's social needs rather than commercial purposes. The demand for train services is relatively high as it costs only RM3.00 to get to Kuala Krai from Dabong.

In tandem with the local plan, The Star dated 27 March 2016 reported that rural people in Kelantan are experiencing insufficient transport accessibility to meet their basic needs. The limited transport services have resulted in difficulties to obtain basic opportunities. Many of them have been solely dependent on the train services in their areas to help them travel. There are also hired car services but the charges are high, especially to get to Kuala Krai town. Therefore, many of the villagers prefer to travel by train instead. The studies conducted by Jackson et al. (2012) and Hasiak et al. (2016) also indicate that trains are preferred to buses in general, and bus or coach services are considered to complement rail services.

\section{Literature Review}

\subsection{Concept of accessibility}

Accessibility is a vital concept, and a powerful evaluation criterion in many fields and it has been used in the transportation planning field for more than 40 years (Handy, 2002). According to Geurs and Wee (2004), accessibility is a concept used in a number of scientific fields including transport planning, urban planning and geography, that contributes to a vital role in the policy-making process. Specifically, the term has been used to monitor 
and evaluate the effectiveness of policy and decision making in fields such as transportation planning (Morris et al., 1979), spatial technologies (Shen, 1998), geography (Kwan \& Weber, 2003), land use allocation (Guy, 1983 \& Hansen, 1959) and social exclusion (Kamruzzaman \& Hine, 2012; Mahapa \& Mashiri, 2001; Paez, Mercado, Farber, Morency \& Roorda, 2010; Preston \& Raje, 2007). However, accessibility has often been criticised as being broad and ambiguous besides difficult to measure (Doi, Kii \& Nakanishi, 2008; Morris et al., 1979).

Accessibility is defined and operationalised in several ways, and has taken a variety of meanings and several definitions that have been offered by various scholars (Velaga et al., 2012). In the transport context, accessibility can be defined as facility or opportunity that can be reached from a given location using as a certain transport system (Gutierrez, 2009). Investment in rural roads has been a major concern of donor agencies and governments in developing countries.

The level of accessibility has tremendous direct and indirect impacts on people and communities. One of the important contributing factors that account for the economic downturn and poor development in rural areas is poor accessibility to services (Sarkar \& Ghosh, 2000). Improving accessibility and reducing accessibility costs are fundamental in achieving many economic, social and environmental objectives (Litman, 2017). Accessibility is defined and operationalised in several ways, and has therefore taken on a variety of meanings. In today's developing world, the reasons for slow economic growth as well as poor development are almost alike at the local and regional levels. These are defined as social exclusions and dispersed locations of rural settlements without proper road connectivity, shortage of adequate transportation services and infrastructure (Sarkar \& Ghosh, 2000).

However, the importance of transport services in the provision of rural accessibility has largely been ignored (Ellis, 1997). Apparently, research on transportation has focused mostly in the urban instead of rural areas. Heilig and Voss (2015) have highlighted that there are very few researches exclusively on regional transport, compared to research on local public transport. Most of the transport research has focused on urban areas, urban planning, urban traffic and urban development. 


\subsection{Transport planning in rural areas}

Poor accessibility in rural areas is a common issue experienced by countries worldwide. Countries like Australia, the United States and Canada are also experiencing poor public transport access in rural areas. According to the Agensi Pengangkutan Awam Darat (APAD), public transport accessibility problems and execution of integrated rural transport systems have stressed the importance of having strong cooperative planning that involves all the three layers of government (federal, state and local authorities) (SPAD, 2012). Other than looking at an efficient institutional framework as mentioned by APAD, Shoup and Homa (2010) indicated the importance of integrating modes of transportation. According to their work, transport planning should also integrate the various modes of transport available (cars, walking, cycling, transit) as an initiative to strengthen support for land-use plans and economic development purposes (Shoup \& Homa, 2010). At present, according to Litman (2013), transportation planning is focused on accessibility-based analysis (which evaluates transport system performance based on the ability of people and businesses to reach their desired services and activities).

Although rural areas have lower population concentrations as compared to the urban and even suburban areas, they are perceived as one of the most challenging surroundings for adequate public transport delivery. Due to its isolated travel patterns and limited travel demand, the provision of high quality and high occupancy public transport services are rather difficult to implement (White, 2009). In the United Kingdom (UK) for instance, in serving the least-occupied areas, demand-responsive transport services are practically similar to those used in Netherlands and Switzerland (UK's Commission for Integrated Transport, 2008). Donnges (2003) clearly argued that rural transport planning needs to be based on its people, their problems and needs as well as the understanding of the potentials of an area. As such, planners at the local level are in the best position to identify and address the real transport needs in their areas of jurisdiction. Ultimately, the process of improving rural access should always start with the identification of the real access needs and transport patterns of the rural people. Donnges further states that rural infrastructure projects should be able to address the real needs of the local people and should optimise the use of local resources from a cost perspective. To an extent, they should be planned, designed, 
implemented and maintained in the communities, by the communities and for the communities. Consequently, small-scale rural infrastructure projects or top-down planning without community participation often turned out to be ineffective and a waste of resources. Investments in rural areas that would benefit the rural people have often received secondary priority (Donnges, 2003).

In essence, rural transport planning needs sufficient planning data and well-trained staff. However, very often both are lacking, particularly at the district level. Nevertheless, planning of rural transport services and to a lesser extent infrastructure at the village level, are very much at the initial stages. These activities have been neglected by default, so the local community and the market has to deal with them. There is a need to find effective ways of working with and strengthening local communities and institutions as well as markets to work together to improve the overall performance (Hine, 2014). Nevertheless, rural transport plays an essential role in achieving more than half of the Sustainable Development Goals (SDGs) and fulfilling the 2030 Agenda for sustainable development to leave no one behind. The delivery of safe, reliable, and affordable rural transport infrastructure and services is crucial to ease rural access to markets and services such as education and health facilities, enterprise and employment opportunities, increase agricultural production, develop modern supply chains for crop delivery, prevent food loss, and therefore achieve zero hunger and poverty at once (Cook et al., 2017).

\subsection{Institutional challenges in the implementation process}

At the policy and organisational levels, institutional factors may strongly affect the opportunities for the overall planning of the network (Mulley, Nelson \& Nielsen, 2005). Transportation planning must be cooperative because no single agency has responsibility for the entire transportation system. State and local agencies can achieve significant gains by incorporating environmental and community values into transportation decisions early in planning and carry these considerations through project development and delivery. By enhancing inter-agency participation and coordination efforts and procedures, transportation planning agencies can establish a more positive working relationship with resource agencies and the public (Sarkar \& Dash, 2011). Meanwhile, improvements to inter-agency 
relationships may help to resolve differences on key issues as transportation programmes and projects move from planning to design and implementation.

Major obstacles remain to translate accessibility policies into the provision of comprehensive transport. Inadequate monitoring and implementation of compliance with existing accessibility legislation are widely cited as the key weaknesses in attempts to provide inclusive transport in developing countries. Legislation has rarely been matched by adequate and detailed regulatory frameworks and has therefore generated a very limited response on the ground (Venter, Rickert \& Maunder, 2003). Rural communities often face challenges related to fragmentation and duplication of services intertwined with different programs. A lack of coordination among local and state agencies can lead to the inefficient use of limited resources. Poor communication in workforce programmes continues to be a problem in many rural regions. While several federal agencies and various local organisations are involved in coordinating the transportation systems and programmes, integrating of services is important (HHS, 2018).

Clearly, rural transport planning needs to be based on the understanding of the potentials of an area, its people and their problems and needs. Planners at the local level are in the best position to identify and address the real transport needs in their areas of jurisdiction. The decentralisation process that has started and is now underway in many countries in the Asia-Pacific region, enables a situation in which local government units can plan, provide and manage the rural transport system (Donnges, 2003). Nevertheless, making sure that local leaders in rural areas have adequate policy and institutional knowledge, organisational capacity and advocacy skills to participate effectively in transportation planning is another key challenge (Kidder, 2006). Sometimes local government bodies are ineffective in the absence of a meaningful transfer of executive and budgetary powers. This is due to the absence of active participation by the population in the decisionmaking process and a lack of suitable local-level planning tools (Sarkar \& Dash, 2011).

There is no cheap solution in providing an accessible rural transport system. Public transport has to be affordable and accessible to all groups in the population and especially to those who do not have any car or individual motorised vehicle. Funds to finance transportation projects have always been short in the underdeveloped and developing countries Funding for rural transportation involves many stakeholders. Funding is provided and divided 
along many different lines; among federal, state and local governments, among states, between rural and urban areas, and among various types of transportation systems (Kidder, 2006). Funds are needed to finance construction of new projects and maintenance of the old ones, and the supply needs to be regular and adequate (Masood, Naqvi \& Khan, 2011).

In explaining the institutional challenges in the implementation process, primary theories in public policy, namely the implementation theories (topdown and bottom-up) and organisational environment theory are applied. The application of both theories is to better explain and understand the respondents' answers to the "how" and "why" questions that were asked in the interviews. In this study, the top-down approach would explain the roles of the central actors in policymaking, while the bottom-up approach would support the local implementation structure in the rural transport plan. Nevertheless, the bottom-up approach also focuses on strategic interaction among multiple actors in a policy network, the interplay of the three tiers of government in implementing a rural transport plan in the study area. The organisational environment theory would supplement the implementation theories by further understanding the organisational interactions among the tiers of government. As stated by Brun (2016), organisational theory is the study of how formally defined organisations in the public, nonprofit, and private sectors interact with the environment to achieve the organisational goals. The focus of the organisational theory is to understand how the organisations fit into larger social systems (e.g., industries, societies) and how it affects their goals, structure, or processes.

\section{Method}

This case study uses a qualitative approach. In-depth interviews were conducted involving 17 policymakers from the three tiers of government. The policymakers at the federal level are from the Ministry of Rural and Regional Development, Plan Malaysia, Kuala Lumpur and Ministry of Transportation. Meanwhile, respondents at the state level consist of policymakers from the State Economic Planning Unit and Plan Malaysia in Kelantan. Another six interviewees were those representing agencies from the local government, namely the Kuala Krai District Council, Dabong District Council and Kuala Krai Works Department. Two federal government agencies operating in the study area from the South Kelantan Development 
Authority (KESEDAR) and Kelantan Federal Development Department were also interviewed to better understand and explain on the challenges in implementing rural transport accessibility strategies in Kuala Krai, Kelantan.

To better support the responses from the policymakers and to avoid individual bias, responses from two local transport operators in Kuala Krai and two transport experts from a public university were included. According to Yin (2003), interview is proven to be one of the most vital sources used to collect case study data. Four emerging themes were identified from the interviews and discussed in the results and discussion sections. An in-depth semi-structured interview protocol was used to guide the interview process. The interviews conducted were aligned with the ethical procedures of the university and prior consent from the interviewees was obtained. The informant's identities were kept confidential and their names were replaced with alphabetical codes such as PM for policymakers, TE for transport experts and TSP for transport service providers.

\section{Results}

This section looks at the empirical findings obtained from the interviews. The interview data reflected the in-depth insights from the three tiers of government, transport service providers in Kuala Krai, and transport experts who are academicians from public universities specialising in rural transport planning. The institutional challenges are grouped into three main themes namely poor communication and coordination, lack of experts in transport planning and limited financial resources.

\subsection{Poor communication and coordination}

Lack of coordination has been cited as one of the primary factors that weakens the implementation of the rural transport plan in Kuala Krai, Kelantan. This scenario is again entrenched by the fragmentation of authorities who are involved in the transportation sector. A senior officer of the federal transportation authority emphasised that the absence of a proper platform to discuss transportation issues in Malaysia is obvious and the federal government is taking this issue seriously by saying that: 
We do not have a formal platform where we can consult one another. Yes, this is the thing we (have) already realised as a shortcoming that we will address in our NTP where we can have proper platform not only for local councils but (also) all transportation-related agencies. So, we can sit together and we can streamline whatever strategies we have (PM3).

An engineer from the Department of Works shared his experience on this issue:

Throughout my experience working with the federal agency in Kuala Krai, this matter (coordination) is not well managed and sometimes we do not know who built this road... that road...(PM10).

The need for coordination is undoubtedly seen as important in the related government agencies in transportation and the same issue is again raised by a local government officer. He professed his opinion with slight frustration as stated below:

There is supposed to be coordination among the agencies but unfortunately that is not happening (PM11).

In the meantime, a local government officer further stressed the redundancy of projects between the state and federal government agencies as quite obvious. His justification is mentioned as follows:

In handling rural roads there are two agencies involved, state and federal agencies. Sometimes roads assisted by (the) state are redundant with (the) federal plans (PM11).

\subsection{Lack of experts in transport planning}

Local authorities have lacked experts in finance and planning. Most of the planning works are actually undertaken by the experts at the state government level and transport planners are virtually absent at the local government level. The assistant planners are overloaded with heavy administrative work that has caused them to be less exposed to the actual 
planning tasks. A transport expert who is also an academician put forward her experience in this way:

I am dealing with a local authority and they do not have a planner, they have assistant planner. Assistant planner, they do not have much technical tasks because they need to do administrative tasks as well... their job scope is diluted and they do not deal with big projects like the urban planners... the planning work itself is quite limited and in the rural areas there are not much of development proposals (TE2).

Another transport expert who is also an academician seems to be frustrated over this matter. He stressed that it is not just the local government but the state government that also has a deficit of experts where those who are supposed to plan are not well specialised in their field. He then suggested that the state government's planners should undergo short courses on planning especially on transport planning. He further mentioned that there are only a few transport experts in Malaysia. He voiced his frustration by saying:

“...there are not many transport experts in Malaysia. The officers who managed transportation matters in the state are sometimes having zero knowledge on transportation..." (TE1)

Insufficient knowledge among the officers in rural planning is seen as rather critical at the local government level. A local government engineer shared his opinion on this matter:

Perhaps at the local level we do not have the expertise... projects would go haywire if they were managed by the local level (PM10).

\subsection{Limited financial resources}

From the interviews conducted, it was found that the most critical issues in implementing rural transport plans were a shortage of funds and personnel. Almost all interviewees raised the shortage of funds as an important issue in Kelantan due to the state's different political views. Other than having 
different political views, Kelantan is also often affected by heavy floods that damage most of the infrastructure, like roads, bridges and other facilities. One of the state officials voiced her concern over this matter by saying that transportation projects are often expensive, and it is impossible for the state to cover all the transportation projects without financial aid from the federal government. She voiced her concern wisely:

To implement a policy, of course we need planning and secondly is financial aid from the federal (government). All projects involved costs and road projects are often expensive. If state were to implement all road projects, it is impossible to cover the whole (of) Kelantan. We do have budget but only enough to maintain the existing roads as every year we are affected by floods that caused damages to (the) main roads. So, any transportation projects, there must be aid from the federal (government) (PM5).

Meanwhile, at the local level, an officer was vocal in expressing his frustration over the shortage of funds when he cited his belief that Kelantan is never prioritised by the federal government due to the different political beliefs of the state. He put across his frustration as:

Yes, we do have suggestions on how to improve the rural transport accessibility in our local plan however we do not have budget to implement such projects. We as the local authority can only suggest but it is beyond our power. Not just in local plan, rural transport initiatives are also available in the Malaysian Plan and the National Physical Plan, but no implementation is carried out due to (the) shortage of budget. We proposed for a bridge to connect one of the areas (Pasir Klang) that is separated by river since 1998 but until 2018, there's nothing (PM9).

A local transport operator also commented on the delay of the budget from the federal government. Due to the delays, discontent among workers transpired because they did not get paid promptly:

In 2010 there was no budget allocation from SPAD at that time and due to that situation, we have to close several bus routes and the circumstances had brought negative effects to users (TSP1). 


\section{Discussion}

\subsection{Communication and coordination gap}

In Kuala Krai, poor communication was said to be obvious in the upper-level agencies that mostly involved the federal government's agencies in Kelantan. There were indications that officers from the federal agencies communicated less with officers at the state level. A similar scenario was also explained by Raja Noriza (2006) in her study on the implementation of urban transport policy in the Klang Valley. Her study found that the detachment of the federal government from local affairs had paralysed the implementation of urban transport policy. Again, this scenario explains the importance of effective communication among government agencies in formulating and implementing the desired policy.

As a consequence of ineffective mutual integration between the government agencies, whether at the federal, state or local levels, the divergence of policy interests have further caused fragmentation among these agencies. The uncoordinated authorities in the government agencies would encounter difficulties in implementing effective transport plans and initiatives. Apparently, communication within and between organisations is a complex and difficult process. In transmitting messages/policies downward in an organisation, or from one organisation to another, communicators inevitably distort them both intentionally and unintentionally (Downs, 1967). In light of this, top-down theorists, Van Meter and Van Horn (1975), stressed the importance of implementers to act on the policy objectives and standards accordingly. Therefore, the prospects of effective implementation will be enhanced by the clarity of communication in which standards and objectives are stated and by the accuracy and consistency with which they are communicated.

Peters (2018) argued that the redundancy of programmes was mainly caused by coordination problems. Apparently, coordination appears to be an issue when organisations have different ideas about good policies and the ways to address problems. If these organisations can reach some basic agreement on the nature of the problem and perhaps on the means of addressing these problems, then more effective coordination, and more efficient policies may emerge. 


\subsection{Low capacity and capability at local level}

From the interviews conducted with the policymakers, at the federal, state and local levels, and transport experts, and academicians from a public university, the interviewees stressed the absence of transport experts and planners especially at the local government level, that has apparently paralysed the rural transport system. One of the transport experts who is also an academician mentioned that "...when I asked the assistant planner (local level) to comment on my students' projects on local planning, he was having a hard time to understand..." (TE2).

The shortage of skilled professional in handling transport matters, especially at the local level, is obvious in the case of Kuala Krai. One of the transport experts interviewed suggested the state and local officers should undergo short courses on transport planning. According to him "... you must have knowledge in order to operate a transport system..." (TE1). The lack of transport experts especially at the local government level is due to the absence of a specific transport department that is responsible in handling transport matters, especially in dealing with transport planning and implementation issues. In light of this issue, Zakaria (2003) argued that the lack of urban planners in the public sector has allowed private and foreign aid agencies to propose development plans. This phenomenon is said to be ineffective in reflecting the actual needs of the people, especially the poor.

As constituted in the Town and Country Planning Act 1976, the local authorities are responsible for the regulation, control and planning of development and use of all land and buildings in their areas. The local authorities are also responsible for undertaking activities that can promote the advancement of planning in land use. This authority is also responsible for the preparation and implementation of the local plans within their jurisdiction. However, a lack of capable planners and an inability at the local level can lead to ineffective implementation policies. In the case of Kuala Krai, only assistant planners are available to take control over planning matters in the area.

\subsection{Financial insecurity}

From the interviews, the state and local officials shared the problems encountered in securing a sufficient budget to implement the development of 
the state, including transportation. Due to the highly centralised Malaysian administrative system, state responsibilities and public finances are in the hands of the federal government. States with poorer economies are heavily dependent on the federal government in almost every sector including waste management, education, transportation and healthcare services (Oliveira, 2016). In the case of Kuala Krai, the state and local officials raised the concern of budget constraints in implementing most of the rural transport initiatives. as “... in Kelantan currently...budget from the federal (government) is coming in slow..." (PM10).

Raja Noriza (2006) in her study on the implementation of urban transport policy in the Klang Valley, Malaysia, suggested that there is limited fiscal distribution by the federal government to the state government. She further added that centralisation has caused a lack of autonomy in the local governments in the Klang Valley to implement their transport initiatives. Similarly, in Kuala Krai, most of the rural transport initiatives have failed to be implemented due to the limited financial incentives, as the local government is dependent on the state budget. In overcoming the alarming budget deficit issue in the state, prudent spending based on priorities is practiced at both the state and local government levels. Consequently, the budget deficit issue has negatively affected the rural community in Kuala Krai as many local buses have terminated their services. This phenomenon has intensely limited the users to transport accessibility and mobility in performing their daily activities, especially those living in the rural areas. One of the transport operators in Kuala Krai mentioned that "... we have to close several bus routes and it has brought negative effects to the users ..." (TSP1).

\section{Limitations}

Since the study is a single case study focusing on only one individual area, it cannot be generalised for other rural areas in Malaysia. Although this study has in-depth explanations on the realities of rural transport accessibility in Kuala Krai, Kelantan, the findings are exclusively based on the nature of the study area. Therefore, the rural transport accessibility scenario in the study area might not be similar to other rural areas, and thus it may not represent the entire rural transport scenario in other places. 


\section{Conclusion}

Fragmentation of authorities due to the poor coordination were identified as the main challenges in implementing a successful government policy in transportation. Having said that, there is also an urgent need to strengthen the capacity and capability of the existing personnel, especially at the local government level. In the case of Kuala Krai, most of the planning works were undertaken by the planner at the state level and the assistant planners at the local level were often burdened with heavy administrative tasks rather than planning. Nevertheless, the absence of a proper platform to discuss transport-related issues has further resulted in poor communication and coordination issues among the different tiers of government.

An understanding of policy implementation is closely interrelated with the understanding of organisation. Government plays an ultimate role in solving rural transport issues faced by the villagers. As the rural transport plan is developed based on the top-down premise, the actual on-the-ground transport issues faced by the villagers have failed to attract the attention of policymakers. Effective policy implementation can only be achieved when the three different tiers of government are able to work collectively and harmoniously. Thus, a strong organisational structure between the three different tiers of government would lead to an effective implementation of the rural transport plan in the study area as mentioned by the policymakers during the interviews. A study conducted by the Massachusetts Institute of Technology (MIT) with the collaboration of Malaysian Technology University (UTM) under the Malaysia Sustainable Cities Programme has found that strong intra and inter-governmental coordination is needed among the three different levels of government in implementing government policies, especially when it involves multi-sectoral policies that need participation from various levels and departments in the state (Oliveira, 2016).

The decision-making process in the Malaysian administrative system has always been heavily centralised. Thus, the actual transport needs of the villagers are not successfully captured and often neglected by the policymakers as most of the decision-making processes have failed to include the public or the grassroots. Several federal policymakers have mentioned that it is better if the policymaking process is centralised as the budget for implementing policies comes mainly from the federal 
government. Therefore, a top-down approach is more preferred than the bottom-up approach in formulating and implementing policies desired by the local government. However, there are several policymakers including the transport experts who believe that the bottom-up approach is the best approach in understanding the actual needs of the people by involving them directly in the policymaking process. In summary, top-down policy implementation is very hierarchical, while the bottom-up implementation reflects the interests of the people at large. The bottom-up approach is seen to be more realistic and practical compared to the top-down approach and is more practically conducive in a democratic system (deLeon \& deLeon, 2002).

It is vital for planners and policymakers to capture the actual transport needs of rapidly growing rural populations in their areas. By successfully addressing the actual transport needs of the people, their lives can be significantly improved as mobility and accessibility are important factors in rural life. Lack of adequate data on the actual transport needs and travel behaviour of a particular community can negatively influence the direction of rural transport provision as a result. The absence of a lead agency has led to poorly defined coordination and roles among the existing government agencies. The effectiveness of policy implementation is very much dependent upon the political interest of the government. In the Malaysian democratic parliamentary system, political factors are seen as the most important element that influence development projects, either in the urban or rural areas. Therefore, it is ultimately important for the government agencies (federal, state and local) to work closely with one another to achieve success in the planning and implementation of an accessible rural transport system.

\section{Acknowledgement}

My heartfelt gratitude to the policymakers, transport service providers, transport experts and the villagers who were willing to participate in this study by sharing their knowledge and experience. The sincerity of the villagers in welcoming me to their village and the hospitality they provided during my stay in Kuala Krai are greatly appreciated. 


\section{References}

Azmi, A. A., \& Fanim, M. A., (2012). Transforming the land public transport system in Malaysia. Journeys, 8, 30-37. https://www.academia. edu/31621456/J12_May_p30Azmi_Bin_ABDUL_AZIZ_Transforming the_Land_Public_Transport_System_in_Malaysia.pdf

Barrett, S., \& Fudge, C. (1981). Policy and Action: Essays on the Implementation of Public Policy. London: Methuen.

Brun, L. C. (2016). Organizational theory and public policy. In Schechter, S., Vontz, T. S., Birkland, T. A., Graber, M. A. \& Patrick, J. J. (Eds.), American Governance (pp. 14-16). USA: Macmillan.

Cook, J., Huizenga, C., Petts, R., Visser, C., \& Yiu, A. (2017). The contribution of rural transport to achieve the sustainable development goals. Research Community for Access Partnership (ReCAP). https://sustainabledevelopment.un.org/content/documents/16933The Contribution_of_Rural_Transport_to_Achieve_the_Sustainable_ Development_Goals.pdf

Deleon, P., \& deLeon, L. (2002). What ever happened to policy implementation? An alternative approach. Journal of Public Administration Research and Theory, 12(4), 467-492. https://www.jstor. org/stable/3525857

Doi, K., Kii, M., \& Nakanishi, H. (2008). An integrated evaluation method of accessibility, quality of life and social interaction. Environment and Planning B: Urban Analytics and City Science, 35(6), 1098-1116. https:// doi.org/10.1068/b3315t

Donnges, C. (2003). Improving access in rural areas. Guidelines for integrated rural accessibility planning. Bangkok: International Labor Organization. https://www.ilo.org/wcmsp5/groups/public/---asia/---robangkok/documents /publication/wcms_bk_pb_216_en.pdf

Ellis, S. D. (1997). Key issues in rural transport in developing countries. Crowthorne: Transport Research Laboratory Report 260. https://worldcat. org/issn/09684107

Geurs, K. T., \& Wee, B. V. (2004). Accessibility evaluation of land-use and transport strategies: review and research directions. Journal of Transport Geography, 12, 127-140. https://doi.org/ 10.1016/j.jtrangeo.2003.10.005

Gutiérrez, J. (2009). Transport and accessibility. In R. Kitchin, \& N. Thrift (Eds.), International Encyclopedia of Human Geography (pp. 410- 
417). Oxford: Elsevier. https://www.elsevier.com/books/internationalencyclopedia-of-human-geography/kitchin/978-0-08-044911-1

Guy, C. M. (1983). The assessment of access to local shopping opportunities: A comparison of accessibility measures. Environment and Planning B: Planning and Design, 10(2), 219-237. https://doi.org/10.1068/b100219 Handy, S. (2002, May). Accessibility vs. mobility enhancing strategies for addressing automobile dependence in the U.S. Paper presented at the European Conference of Ministers of Transport, Paris. https:// escholarship.org/uc/item $/ 5 \mathrm{kn} 4 \mathrm{~s} 4 \mathrm{pb}$

Hansen, W. G. (1959). How accessibility shapes land use. Journal of American Institute of Planners, 25(1), 73-76. https://doi. org/10.1080/01944365908978307

Hasiak, S., Hasiak, F., \& Egea, A. (2016). Coach and train: Differences in individuals perception of these modes. Transportation Research Procedia, 14, 1706-1715. https://doi.org/10.1016/j.trpro.2016.05.136f

Heilig, L., \& Voß, S. (2015). A scientometric analysis of public transport research. Journal of Public Transportation, 18(2), 111-141. https://doi. org/10.5038/2375-0901.18.2.8

Jackson, J., Johnson, D., \& Nash, C. (2012). On the willingness to pay for rural rail service level changes. Research in Transportation Business and Management, 4, 104-113. https://doi.org/10.1016/j.rtbm.2012.06.006

Kamruzzaman, M., \& Hine, J. (2012). Analysis of rural activity spaces and transport disadvantage using a multi-method approach. Transport Policy, 19(1), 105-120. https://doi.org/10.1016/j.tranpol.2011.09.007

Kidder, B. (2006). The challenges of rural transportation. United States of America: Western Rural Development Center. https://pdfs. semanticscholar.org/e605/8d766f2efe97bfa3723dcae79e4216529bda.pdf

Kwan, M. P., \& Weber, J. (2003). Individual accessibility revisited: Implications for geographical analysis in the twentyfirst century. Geographical Analysis, 35(4), 341-353. https://doi. org/10.1111/j.1538-4632. 2003.tb01119.x

Land Public Transport Commission (2012). Greater KL/Klang Valley Land Public Transport Master Plan. Malaysia: Land Public Transport Commission.

Laws of Malaysia (1976). Town and Country Planning Act. Petaling Jaya, Selangor: International Law Book Services.

Litman, T. (2013). The new transportation planning paradigm. ITE Journal 
(Institute of Transportation Engineers), 83(6), 20-28. https://www.vtpi. org/paradigm.pdf

Litman, T. (2017). Accessibility for transportation planning. Measuring people's ability to reach desired goods and activities. Canada: Victoria Transport Policy Institute. https://www.vtpi.org/access.pdf

Mahapa, S. M., \& Mashiri, M. (2001). Social exclusion and rural transport: Gender aspects of a road improvement project in Tshitwe, Northern Province. Development Southern Africa, 18(3), 365-376. https://www. ssatp.org/sites/ssatp/files/publications/HTML/Gender-RG/Source $\% 20 \%$ 20 documents/case $\% 20$ studies/IFRTD\%20Case\%20Summaries/ CSIFR10\%20Social\%20Exclusion\%20RT\%20South\%20Africa.pdf

Masood, M. T., Khan, A., \& Naqvi, H. A. (2011). Transportation problems in developing countries Pakistan: A case-in-point. International Journal of Business and Management, 6(11), 256-266. https://doi.org/ 10.5539/ ijbm.v6n11p256

Morris, J. M., Dumble, P. L., \& Wigan, M. R. (1979). Accessibility indicators for transport planning. Transportation Research Part A: General, 13(2), 91-109. https://doi.org/10.1016/0191-2607(79)90012-8

Mulley, C., Nelson, J. D., \& Nielsen, G. (2005). Network planning for high quality public transport. In 9th Thredbo Conference on Competition and Ownership in Land Transport, Lisbon Technical University (pp. 331354), Lisbon. Portugal: Lisbon Technical University.

Ngah, I. (2015). Towards sustainable rural development and planning in Malaysia. https://doi.org/10.13140/RG.2.1.4760.9047

Oliveira, P.d.J.A (2016). Bridging governmental relations in urban management: Cases of solid waste management and climate change in two Malaysian states. MIT-UTM Malaysia Sustainable Cities Program, 1-24. https://scienceimpact.mit.edu/sites/default/files/documents/Oliveira. pdf

Páez, A., Mercado, R. G., Farber, S., Morency, C., \& Roorda, M. (2010). Relative accessibility deprivation indicators for urban settings: definitions and application to food deserts in Montreal. Urban Studies, 47(7), 1415-1438. https://doi.org/10.1177/0042098009353626

Peters, B. G. (2018). The challenge of policy coordination. Policy Design and Practice, 1(1), 1-11. https://doi.org/10.1080/25741292.2018.1437946

Preston, J., \& Rajé, F. (2007). Accessibility, mobility and transport-related social exclusion. Journal of Transport Geography, 15(3), 151-160. 
https://doi.org/10.1016/j.jtrangeo.2006.05.002

Raja Noriza, R. A. (2006). The implementation of urban transport policy in the Klang Valley, Malaysia. (Doctoral dissertation, University of Nottingham, UK).

Sarkar, A. K., \& Dash, M. (2011). Quantification of accessibility and prioritization of villages for local level planning. Transport and Communication Bulletin for Asia and the Pacific, 81, 1-22. https://www. unescap.org/sites/default/files/bulletin81_Article-1.pdf

Sarkar, A. K., \& Ghosh, D. (2000). Identification and prioritization of access problems in rural areas. Development Southern Africa, 17(1), 149-156.

Shen, Q. (1998). Location characteristics of inner-city neighborhoods and employment accessibility of low-wage workers. Environment and Planning B, 25(3), 345-365. https://doi.org/10.1068/b250345

Shoup, L., \& Homa. B. (2010). Principles for Improving Options in Rural and Small Town Communities. Washington, D. C.: Transportation for America.

Starkey, P., \& Hine, J. (2014). Poverty and sustainable transport: How transport affects poor people with policy implication for poverty reduction. United Kingdom: Department for International Development. https/file://C:/Users/USER/Downloads/ODI-UNHabitat-SLoCaTTransport-Poverty-Review-StarkeyHine-1411052.pdf

UK Commission for Integrated Transport (2008). A new approach to rural public transport. https://www.cfit.gov.uk/docs/2008/rpt/report/pdf/rpt.pdf

U.S. Department of Health and Human Services (2018). 2018 Annual Report. United States: Department of Health and Human Services. https://www.hhs.gov/sites/default/files/2018-annual-report.pdf

Van Meter, D., \& Van Horn, C. (1975). The policy implementation process: A conceptual framework. Administration \& Society, 6(4), 445-448. https://doi.org/10.1177/009539977500600404

Velaga, N. R., Beecroft, M., Nelson, J. D., Corsar, D., \& Edwards, P. (2012). Transport poverty meets the digital divide: Accessibility and connectivity in rural communities. Journal of Transport Geography, 21, 102-112. https://doi.org/10.1016/j.jtrangeo.2011.12.005

Venter, C. J., Rickert, T., \& Maunder, D. (2003). From basic rights to full access: Elements of current accessibility practice in developing countries. Transportation Research Record: Journal of the Transportation Research Board, 1848(1), 79-85. https://doi.org/10.3141\%2F1848-11 
White, P. (2009). Public Transport: Its Planning, Management and Operation ( $5^{\text {th }}$ ed.). London: Routledge.

World Bank (2007). World Development Indicators. Washington DC: World Bank.

Yin, R. K. (2003). Case Study Research: Design and Methods (3 ${ }^{\text {rd }}$ ed.). California: Sage Publications.

Yiu, A. (2017). Promotion of sustainable rural access in the implementation of the 2030 global agenda on sustainable development: Key messages consultation analysis. https://assets.publishing.service. gov.uk/media/5979c7e9e5274a737600000a/SLOCAT_2017 KeyMessagesConsultationAnalysis_ReCAP_KMN2089A_170405.pdf Zakaria, Z. (2003). The Institutional Framework for Urban Transportation and Land Use Planning and Management in the Globalizing Kuala Lumpur Region. Research paperwork.http://web.mit.edu/ mtransgroup/reports/reports\%20pdf\%203-2504/Zakaria\%20_2003_\%20 Institutional $\% 20$ Framework $\% 20$ for $\% 20$ Urban $\% 20$ Transport $\% 85$.pdf 